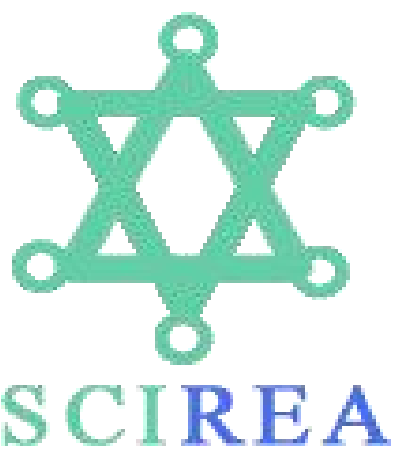

SCIREA Journal of Sociology

http://www.scirea.org/journal/Sociology

January 10, 2022

Volume 6, Issue 1, February 2022

https://doi.org/10.54647/sociology 84726

\title{
Are the Balkans tolerant?
}

\section{Lilia DIMOVA ${ }^{1}$, Martin DIMOV ${ }^{2}$}

${ }^{1}$ Agency for Social Analyses (ASA), Bulgaria

${ }^{2}$ Gem Seek Company, Bulgaria

Email: lilia.dimova@consultant.bg (Lilia DIMOVA),dimov.martin@gmail.com (Martin DIMOV)

\begin{abstract}
This study focuses on Balkans' tolerance to 'different others', to people with specific sexuality and to migrants. Tolerance is defined as a value construct and multi-dimensional social phenomenon combining four interconnected components: perception, recognition, appreciation, and acceptance of diversity. Based on ESS data we calculated tolerance indexes and run random forest algorithms to measure the levels of tolerance and key influencers in Bulgaria, Serbia, Slovenia, Croatia, Montenegro and the Greek part of Cyprus. Results found that their abstract tolerance is higher while target tolerance is significantly lower compared to that in the rest of Europe. The tolerance determinants range differently in each society, but life satisfaction, living standard, religion, trust in national institutions stand out among the top common vectors.
\end{abstract}

Keywords: tolerance; index of tolerance; random forest algorithm; ESS; different others; people with specific sexuality; migrants. 


\section{Introduction}

The geopolitical location of the Balkans has been a priority of the Top Players for centuries. Nowadays the Balkans play a rather important role in Europe as a transit corridor of the migrant flows to the Central and Northern parts of the continent. Even because of that, it is an actual scientific challenge to discover more about the social and cultural climate there, to have a better understanding of specific attitudes towards those who are different, and to have a strongest grasp of how people from the Balkans would feel living together with such 'different others'. 'Are the Balkans tolerant?' is our key research question, to which this study seeks answers.

We have constructed our analysis starting with the implemented conceptual framework, based on a theoretical overview, followed by an explanation of the applied empirical basis and statistical methods; then the results are presented and at the end are put issues for general discussion.

\section{Conceptual framework}

'The concept of tolerance is in a state of disarray', alarmed Ferrar (1976) almost a half century ago and this statement still sounds up-to-date. Even so, tolerance is considered difficult to be unequivocally defined, despite the huge literature dealing with its meaning. one of the reasons is that it is among the few social phenomena that have contradictory nature and could be both morally good and bad, depending on the target and the context.

Usually, tolerance is discussed as a complex, paradoxical, and multidimensional construct. Various forms of 'US-THEM' distinctions have been proposed, various discourses characterize these distinctions. Such variety of understandings raise different empirical questions and have different implications for the subject positions of those who are tolerant and those who are tolerated. (Blommaert et al., 2020; Brown, 2006 ). Mainly because of that, the discussion about definition of tolerance in its social context continue without reaching a consensus between researchers, social scientists, philosophers, psychologists, politicians. As a rule, each guild looks at tolerance from the positions of its own category model, research or political purposes, specific toolkit.

The common vector in the variety of definitions seems to be limited to the willingness of a person/community/society to accept diversity, to be open-minded to somebody who is 
different, even disliked. However, ongoing discussions are not restricted only to the mindset to embrace diversity and possibility to coexist with it. Among the actual topics of current debates is whether tolerance is a value construct, i.e., a part of a person's (or community's) value structure and therefore does not generally have a specific addressee, or it is always a matter of attitude to a fixed object. Furthermore, social scientists do not have a uniform opinion about whether tolerance is necessarily associated with prejudice, or it has an independent existence; whether it is a multiple dimensional concept or not; whether it requires more than one empirical approach in measuring its level and direction; and many others. The positive effect of each view however, contributes to a better understanding the meaning of the paradigm, as well as to developing effective policies towards establishing a tolerant culture in general.

In the scientific debated the scales are more inclined towards the perception of tolerance as multi-dimensional construct. (Ferrar 1976; Blommaert et al., 2020; Verkuyten at al., 2021). Forst (2013) describes four concepts of tolerance, which, in his view, are 'different, historically developed understandings of what toleration consists in' and 'may also be understood as conflicts between these conceptions'. In short, his conceptions are: 1) permission; 2) coexistence; 3) respect; 4) esteem. In the resent works, Forst argues that 'the discussion so far implies that toleration is a normatively dependent concept', which for him means that 'by itself it cannot provide the substantive reasons for objection, acceptance, and rejection.' (Forst 2017)

Our understanding of tolerance is close to that of Verkuyten and Kollar who distinguish two broad conceptualizations of tolerance based on classical (endurance and condoning) and modern (prejudiced and racist) grasp of the phenomenon. (Verkuyten at al., 2021) According to them, the classical tolerance discourse focuses on forbearance and enduring things that one disapproves of. The modern meaning of tolerance is related to broad-mindedness and full acceptance of cultural differences. Intolerance, on the other hand, is mainly embedded in terms such as prejudice, bigotry, and discrimination. People might understand social tolerance differently than political tolerance, or they 'might use the discourse of tolerance differently in situations in which they do or do not feel threatened by dissenting others'. In general, 'the power of the (in)toleration discourse depends on the meanings that are deployed, the way in which these are used, and who is using them and for which purposes'. (Verkuyten at al., 2021) We also agree with Hjerm's team (Hjerm at al., 2020) who conceptualize tolerance as 'a value orientation towards difference'. They justify their definition as 'abstract and does not capture 
attitudes towards specific out-groups, ideas, or behaviours', and as such it 'allows for the analysis of tolerance within and between societies'. Based on that, they developed new innovative measures to operationalize three aspects of tolerance capturing: 1) acceptance of, 2) respect for, and 3) appreciation of difference in the abstract.

Based on previous theoretical work and after an overview of available empirical achievements, in this study we also consider tolerance as a value construct. To be tolerant, or not, depends on the personal or group value structure, norms and priorities. For us, the key point, the key common vector, the key common denominator among different definitions of tolerance could be summarized to the willingness of accepting diversity, to the frame of mind to appreciate or to coexist with the 'different others', which differ from 'generalized others' or 'significant others'. (Kenton 2013; Crossman, 2020). The 'different others' are not a stable construct or fully occupied by any single social group. Their identification depends on context, but tolerance as a value paradigm is assumed as a general rule as disposition of positiveness towards diversity. However, it should be pointed out, that such disposition is not towards any diversity, but only to those objects that respect the human rights and dignity. Here we do not investigate tolerance in its moral good-bad aspect, but we have that in consideration. Rather, we focus our intention on its positive sides, however keeping in mind that they are not the only ones.

Willingness 'to walk in someone else's shoes' is the value basis on which ground one could be tolerant or not, whether in the classical or modern sense of the concept. (Verkuyten at al., 2021) We enlarge the view that tolerance is a multi-dimensional phenomenon (Ferrar, 1967; Hjerm at al., 2020) one step further. Our conceptual view is that tolerance combines four interconnected dimensions: 1) perception of diversity - it is 'important to a person to listen to people who are different from him/her and even when s/he disagrees with them, s/he still wants to understand them'. (ESS Round 9, 2018); 2) recognition of diversity - a person recognizes the rights of people, different from his/her life style, believes, persuasions, sexual orientations, religion, culture norms, life priorities, etc., to live as they wish.; 3) appreciation/respect of diversity - a person esteems what people, different from him/her, could contribute to the establishment of a better society; 4) acceptance of diversity - a person is willing to live together with people who are 'different others'. The four components cover both the modern and the classical meaning of tolerance, related to broad-mindedness and full or partial acceptance of cultural differences. (Verkuyten at al., 2021). 
That four-dimensional conceptual approach allows to empirically discover different levels of tolerance and to be implemented to any specific target. Its value basis apriory ignores dependency of prejudices to whatever 'out groups', and could be used as a tool to measure tolerance mindset to any 'different others'. Perception of diversity could be viewed as the basis value step of tolerance - i.e., there are people, who are different from us and who we may not like, but their voice deserves to be listened to. The further gradation of tolerance levels goes through a pick-up with those different others, empathy, respect for their rights to follow own culture. However, at these levels the tolerant segment of society keeps its dominant position compared to tolerated portion. This could be changed in the highest tolerance form - that of a full acceptance of cultural differences. With other words, the highest degree of tolerance reflects the readiness of the ethnic majority to coexist with people who follow different cultural patterns in their behaviour, faith, lifestyle.

The discriminative character of tolerance (Witenberg, 2014) is beyond our current interest. However, it is worth mentioning that moral consequences of a tolerant behaviour depend on the tolerated object. Tolerance is a willingness to accept diversity, but not any diversity. The non-critical and in-discriminative acceptance in its extreme forms could lead to recognition of questionable practice and human rights violations - i.e., to tolerate criminals, anti-Semitism, Nazism, xenophobia etc. The slogan 'Zero tolerance to..' to corruption, drugs, vandals and other negative phenomena, for example, indicates that the use of tolerance may not be only positive. Moral judgement of tolerance, inevitably, is rather important, but here we focus only on those aspects, that are not related to breaking the law or human dignity. In particular, our targets here are only 'different others', people with specific sexuality and migrants.

There is another significant aspect of tolerance which is not in the focus of our current study. It is related to the impact of tolerance on social inequality. It should be mentioned, that the function of tolerance in keeping or solving social equality is not unambiguous. Tolerance is always a relationship between tolerating and tolerated individuals or groups. It inevitably poses questions about how the 'tolerators' show their acceptance of the 'others' and how the tolerated 'others' feel to be in such a position. Tolerance from majority to minority social groups usually is considered as something positive for the society. At the same time, willingness to let others live as they desire does not always mean that tolerant people are ready to fully accept tolerated 'others' and to coexist along with them as equals. Thus, the good intentions to recognize the right of others to be as they wish, in fact establishes a specific social inequality - between those who are tolerant and those who are tolerated. In 
other words, in this aspect the tolerant majority keeps its dominant position exhibiting a civilized patience to those who are not like them. This usually is the case when tolerance is predominantly understood in its classical meaning of forbearance and enduring things that one disapproves of. At the same time, people who are different expect not only to be tolerated but to be respected. The marginalized group members are quite sensitive to anything that might cause offense to vulnerable minorities which is considered a sign of intolerance, and therefore should not be accepted but rather silenced or banished (Campbell at al., 2018).

We want to reiterate that our goal is not to make moral judgments about tolerance, nor to determine how it affects social equality. The purpose of this research is to analyze at comparative European perspectives the levels of tolerance and the key influencers on these levels in six Balkans' societies, implementing modern statistical approaches to both abstract and focusing conceptualization of the phenomenon.

Our main research hypotheses could be thus summarized:

First: Compared to other Europeans, people on and around the Balkan Peninsula are characterized by the same high 'abstract tolerance' to the 'different others' (i.e., without fixed targets) and much lower tolerance focused on specific targets like people with different sexuality and migrants.

Second: The Balkans are not a homogeneous part of Europe - different communities and neighboring countries have different levels of tolerance and different influencers on these levels.

Third: The 'US - THEM' tolerance distance depends on the context, but the level of tolerance is a function of the cultural value composition of the given society, community, individuals.

\section{Data and methods}

The empirical basis of this study is data from the ESS Round 9, Third edition (ESS Round 9, 2018). The national representative surveys, conducted in 2018/19 in 29 European countries using unified research methodology and sample designed model, probed 49,519 respondents over 15 years of age through face-to-face interview and CAPI. The data collected is representative for the whole population of the surveyed countries which makes it suitable for cross-nationally comparisons and analytics. 
We focused on six Balkan societies: Bulgaria, Croatia, Serbia, Montenegro, Slovenia and the Greek part of Cyprus among these 29 countries. The main criteria for our target choice were successfully completion of the ESS R9 and Balkans' nationality. The Greek part of Cyprus island was selected because the ESS R9 was conducted there, while the country of Greece missed that round. Our assumption was that Greeks should share similar national culture, values and identity, regardless if they live on an island or on the continent. We have also included Slovenia in our quota as a member of the former Yugoslavia. In total, 9,350 face-toface CAPI interviews have been conducted there.

We have implemented a three-step approach to answer the main research question 'Are the Balkans tolerant?':

First, we've evaluated the level of tolerance by introducing a Tolerance Indexes comprised of four components, as defined above: i.e., tolerance index of understanding of diversity, recognition of diversity, appreciation/evaluation of diversity, acceptance of diversity. Such measure was calculated for every single ESS surveyed countries, including the selected Balkan's societies. The operationalizations of the four tolerance components are a part of the ESS R9 research instrumentarium (ESS Round 9, 2018). The variables used for the index calculations could be seen in Table 1 .

Our statistical approach of calculation the single sub-indexes and the total index of tolerance was based on statistical modeling. The overall tolerance index is a synthetic indicator calculated as a centered average weighted by actual respondents' answers on series of questions covering four different areas of tolerance as shown in Table 1. Targets of tolerance are people with different sexual orientation, immigrants and 'different others'. Tolerance indexes are ranged from -100 (no tolerance) to +100 (high tolerance), and represent an aggregated value of the total and the four sub-indexes. The actual calculation went through three main stages:

1. Calibration of individual variables - each measure, included in the sub-index calculation was individually calibrated so that each scale takes values from -100 to +100 depending on original scales length i.e., 5 to 10 points continuums, so that lower tolerance takes values close to -100 and higher ones - close to +100 . All variables were divided into equal bands with respect to original scale length.

2. Calculation of sub-indexes - based on new coding, a total of four sub-indexes were calculated as row means for each individual respondent. Each variable assumes equal weight. 
3. Calculation of total tolerance index - based on individual respondent's means, the total index was derived as centered average of all four individual sub-indexes.

Overall, countries' indexes were calculated as average of individual respondent's values for the respective society.

Table 1: ESS independent variables for calculating tolerance indexes

\begin{tabular}{|c|c|c|c|}
\hline Sub-Index name & $\begin{array}{l}\text { Number } \\
\text { in the } \\
\text { ESS R9 }\end{array}$ & Variable name & Answer scale \\
\hline \multirow{3}{*}{$\begin{array}{l}\text { Tolerance as } \\
\text { understanding of } \\
\text { diversity }\end{array}$} & HC & $\begin{array}{c}\text { S/He thinks it is important that every } \\
\text { person in the world should be treated } \\
\text { equally. S/He believes everyone should } \\
\text { have equal opportunities in life. }\end{array}$ & \multirow{3}{*}{$\begin{array}{c}\text { 6-point ordinal scale } \\
\text { (Schwartz's battery of } \\
\text { human values): } \\
\text { Very much like me = } 1 \\
\text { Like me }=2 \\
\text { Somewhat like me }=3 \\
\text { A little like me }=4 \\
\text { Not like me }=5 \\
\text { Not like me at all }=6\end{array}$} \\
\hline & HH & $\begin{array}{l}\text { It is important to him/her to listen to } \\
\text { people who are different from him/her. } \\
\text { Even when s/he disagrees with them, } \\
\text { s/he still wants to understand them. }\end{array}$ & \\
\hline & HL & $\begin{array}{l}\text { It's very important to him/her to help the } \\
\text { people around him/her. S/He wants to } \\
\text { care for their well-being. }\end{array}$ & \\
\hline \multirow{3}{*}{$\begin{array}{l}\text { Tolerance as } \\
\text { recognition of diversity }\end{array}$} & B34 & $\begin{array}{l}\text { Gay men and lesbians should be free to } \\
\text { live their own life as they wish. }\end{array}$ & \multirow{3}{*}{$\begin{array}{l}\text { Likert 5-point scale: } \\
\begin{array}{c}1=\text { Agree strongly } \\
2=\text { Agree }\end{array} \\
3=\text { Neither agree, nor } \\
\text { disagree } \\
4=\text { Disagree } \\
5=\text { Disagree strongly }\end{array}$} \\
\hline & B35 & $\begin{array}{l}\text { If a close family member was a gay man } \\
\text { or a lesbian, I would feel ashamed }\end{array}$ & \\
\hline & B36 & $\begin{array}{l}\text { Gay male and lesbian couples should } \\
\text { have the same rights to adopt children as } \\
\text { straight couples }\end{array}$ & \\
\hline \multirow{3}{*}{$\begin{array}{c}\text { Tolerance as } \\
\text { acceptance of diversity }\end{array}$} & B 38 & $\begin{array}{l}\text { To what extent do you think [country] } \\
\text { should allow people of the same race or } \\
\text { ethnic group as most [country]'s people } \\
\text { to come and live here? }\end{array}$ & \multirow{3}{*}{$\begin{array}{l}\text { 4-point ordinary scale: } \\
\text { Allow many to come } \\
\text { and live here } 1 \\
\text { Allow some } 2 \\
\text { Allow a few } 3 \\
\text { Allow none } 4\end{array}$} \\
\hline & B 39 & $\begin{array}{l}\text { How about people of a different race } \\
\text { or ethnic group from most [country] } \\
\text { people? }\end{array}$ & \\
\hline & B 40 & $\begin{array}{c}\text { How about people from the poorer } \\
\text { countries outside Europe? }\end{array}$ & \\
\hline
\end{tabular}




\begin{tabular}{|c|c|c|c|}
\hline \multirow{3}{*}{$\begin{array}{l}\text { Tolerance as } \\
\text { appreciation of } \\
\text { diversity }\end{array}$} & B 41 & $\begin{array}{l}\text { Would you say it is generally bad or } \\
\text { good for [country]'s economy that } \\
\text { people come to live here from other } \\
\text { countries? }\end{array}$ & $\begin{array}{l}\text { 11-point ordinary scale: } \\
\begin{array}{l}00=\text { Bad for the } \\
\text { economy } \\
10=\text { Good for the } \\
\text { economy }\end{array}\end{array}$ \\
\hline & B 42 & $\begin{array}{l}\text { And would you say that [country]'s } \\
\text { cultural life is generally undermined or } \\
\text { enriched by people coming to live here } \\
\text { from other countries? }\end{array}$ & $\begin{array}{c}\text { 11-point ordinary scale: } \\
0=\text { Cultural life } \\
\text { undermined } \\
10=\text { Cultural life } \\
\text { enriched }\end{array}$ \\
\hline & B 43 & $\begin{array}{l}\text { Is [country] made a worse or a better } \\
\text { place to live by people coming to live } \\
\text { here from other countries? }\end{array}$ & $\begin{array}{l}\text { 11-point ordinary scale: } \\
00=\text { Worse place to live } \\
10=\text { Better place to live }\end{array}$ \\
\hline
\end{tabular}

Second, we have ranked the main drivers on tolerance by application of the Random Forest algorithm for each of the selected Balkan's societies. We have created two separate sets of variables, aiming at measuring the influence of each variable on the level of tolerance. In our previous study, we discovered that the level of tolerance depends on socio-demographics and socio-political factors (Dimova at all., 2019). Now we have measured the impact of both. The set of socio-demographic independent variables includes: sex, main activity, residence, marital status, age, social life, education, living standard, religiosity, life satisfaction and happiness. The set of socio-political independent variables consists of: satisfaction of how democratic institutions work in the country, trust in national institutions, individual trust in people, trust in international institutions, left-right political preferences, confidence in prospects for ordinary people to influence political decisions, interest in politics.

The statistical method i.e., Random Forest based on Breiman's work (Breiman 2001), has multiple advantages that clearly leverage the insights and the predictive power of the data as follow:

- $\quad$ Non-linear approach to explain variance in dependent variable;

- Interactivity in building multiple independent models;

- $\quad$ Lesser risk of overfitting;

- Overall highest level of accuracy of prediction as compared to other ML techniques. 
One of the most noticeable advantages of the technique is the possibility to extract the variable importance. For this particular task no prediction of target variable was used. The purpose of running the model was to measure the actual importance of the individual drivers in the context of their mutual dependence and interaction with the other selected variables. We focused on interactive tuning of hyper-parameters, that was made using 20 -fold cross validation greedy algorithm to determine: the number of variables randomly sampled as candidates at each split (mtry) and the minimum number of data points for further splits in a tree. $\left(\min \_n\right)$

We trained our model on 9-fold sub-samples and tested the result on one sub-sample of data which simulated the training dataset for the entire model. The best output of these results was then used in the bagging algorithm. Since this was essentially a regression (rather than classification), we used the min RMSE, i.e., the lowest, as a measure of predictive power of each model turn. Other hyper-parameters were set as constant: number of trees $-1,000$.

Third, we've included the GDP per capita as a macro-level control dimension for the level of the tolerance in Europe and in the Balkans.

\section{Results}

Like all 29 surveyed European countries, people in the Balkans are tolerant in abstract forms, i.e., they declare willingness to accept 'others' in general, just as 'different others', without target specifications. They also live with the standpoint that all people should be treated equally, i.e., they share the so called 'pro-social (or helping) behaviour' aiming to improve the well-being of people in need. (Martela et al., 2016). In comparable perspectives however, the volume of the total tolerance index of the Balkans is four time lower than that of the other European countries. Mean values in Table 2 clearly indicate that tolerance differences between people from the Balkan Peninsula and from the rest of the continent are significant.

Table 2. Tolerance indexes for the European and Balkan societies

(Mean values from -100 to $+\mathbf{1 0 0}$ )

\begin{tabular}{|c|c|c|c|c|c|}
\hline $\begin{array}{c}\text { Average Index for } \\
\text { the countries }\end{array}$ & $\begin{array}{c}\text { Perception } \\
\text { s of the } \\
\text { rights of } \\
\text { 'different } \\
\text { others' }\end{array}$ & $\begin{array}{c}\text { Recognition } \\
\text { the rights of } \\
\text { people with } \\
\text { different } \\
\text { sexuality }\end{array}$ & $\begin{array}{c}\text { Appreciations of } \\
\text { migrants' impact on } \\
\text { the country }\end{array}$ & $\begin{array}{c}\text { Acceptance of } \\
\text { migrant in the } \\
\text { country }\end{array}$ & $\begin{array}{c}\text { Total } \\
\text { Toleranc } \\
\text { e Index }\end{array}$ \\
\hline $\begin{array}{c}23 \text { European } \\
\text { countries }\end{array}$ & 38 & 40 & 6 & 17 & 25 \\
\hline
\end{tabular}




\begin{tabular}{|c|c|c|c|c|c|}
\hline 6 Balkans' societies & 45 & -10 & -10 & -1 & 6 \\
\hline Total & 39 & 31 & 3 & 14 & 21 \\
\hline
\end{tabular}

Compared to the rest of Europe, the Balkans are more tolerant in general, as a state of mind. Most of them declare empathy for people who are not like them. Theoretically, they are willing to recognize the right of the 'different others' to live as they wish, to help those in need, to not impose their own moral norms and living standards on them. However, their tolerance is limited to such abstract paradigms. The specific dimensions of tolerance focused, for instance, on people with different sexuality or migrants, portray them as not so tolerant societies.

Inside the peninsula, we registered differences both as levels of tolerance and as key influencers. Whether it is a Balkan's syndrome or not, whether people there live in their specific environmental world, it is not so easy to say. Although they live close to each other, they are not the same and every given society tries to preserve its national features. Their contact points in the case of tolerance, are limited in denying people who provoke or even disturb their lifestyle and their value model of perceptions about right and wrong. Despite the cross-national differences in the region, people there are impressively united in their abstract tolerance to differences and in their suspicious to people with non-traditional sexual orientation and to the possible impact of migrants on their economies, culture, and way of life.

When it moves from an abstract to a specific object of tolerance, the picture changes sharply both for Europeans, and for the Balkans. It could be seen in more detail in Table 3, where the mean values of the calculated four sub-indexes and total index of tolerance are given by all studied countries.

Table 3. Total and sub-total tolerance indexes by all surveyed countries (Mean values from -100 to + 100)

\begin{tabular}{|c|c|c|c|c|c|}
\hline $\begin{array}{c}\text { Coun } \\
\text { try }\end{array}$ & $\begin{array}{c}\text { Total } \\
\text { Toleran } \\
\text { ce Index }\end{array}$ & $\begin{array}{c}\text { Index of } \\
\text { understanding/per } \\
\text { ception of the } \\
\text { 'different others' }\end{array}$ & $\begin{array}{c}\text { Index of } \\
\text { recognition of } \\
\text { people with } \\
\text { different } \\
\text { sexuality' rights }\end{array}$ & $\begin{array}{c}\text { Index of } \\
\text { appreciation of } \\
\text { immigrants' impact } \\
\text { on the country }\end{array}$ & $\begin{array}{c}\text { Index of } \\
\text { acceptance the } \\
\text { immigrants in } \\
\text { the country }\end{array}$ \\
\hline IS & 63 & 61 & 85 & 39 & 67 \\
\hline SE & 54 & 58 & 73 & 23 & 63 \\
\hline NO & 50 & 52 & 75 & 17 & 55 \\
\hline ES & 46 & 65 & 69 & 16 & 32 \\
\hline
\end{tabular}




\begin{tabular}{|c|c|c|c|c|c|}
\hline $\mathrm{DE}$ & 45 & 60 & 60 & 14 & 47 \\
\hline $\mathrm{CH}$ & 43 & 60 & 54 & 17 & 40 \\
\hline IE & 43 & 58 & 61 & 19 & 34 \\
\hline NL & 43 & 57 & 77 & 12 & 28 \\
\hline $\mathrm{BE}$ & 42 & 58 & 62 & 8 & 40 \\
\hline GB & 42 & 58 & 63 & 13 & 35 \\
\hline $\mathrm{DK}$ & 40 & 57 & 68 & 12 & 25 \\
\hline $\mathrm{PT}$ & 40 & 50 & 45 & 18 & 46 \\
\hline FR & 38 & 57 & 62 & 3 & 32 \\
\hline FI & 36 & 62 & 54 & 18 & 11 \\
\hline SI & 24 & 63 & 21 & -9 & 19 \\
\hline $\mathrm{AT}$ & 23 & 55 & 44 & -4 & -1 \\
\hline HR & 20 & 59 & 3 & 0 & 19 \\
\hline IT & 16 & 45 & 24 & -10 & 5 \\
\hline LV & 13 & 43 & -8 & 7 & 12 \\
\hline $\mathrm{EE}$ & 11 & 41 & 1 & -4 & 4 \\
\hline PL & 8 & 42 & -7 & 10 & -10 \\
\hline RS & 5 & 55 & -30 & -13 & 5 \\
\hline $\mathrm{ME}$ & 4 & 52 & -23 & -8 & -4 \\
\hline $\mathrm{CY}$ & 3 & 66 & -6 & -13 & -36 \\
\hline $\mathrm{LT}$ & -1 & 17 & -36 & 1 & 14 \\
\hline $\mathrm{CZ}$ & -4 & 34 & 13 & -20 & -41 \\
\hline $\mathrm{BG}$ & -6 & 31 & -19 & -18 & -23 \\
\hline SK & -7 & 41 & -18 & -22 & -32 \\
\hline $\mathrm{HU}$ & -19 & 34 & -15 & -22 & -78 \\
\hline
\end{tabular}

$\mathrm{N}=49519 \mathrm{~F} 2 \mathrm{~F}$ interviews

Greek Cypriots are the most tolerant people towards abstract differences in a cross-national European perspective. When however, they face a particular object of tolerance like people with different sexuality or migrants, their tolerance dramatically decreases and they become the most intolerant among the selected six societies. The same Greeks transform their primal 
open-minded attitudes to differentiations from +66 into intolerance, reaching mean values of 6 to people with different sexuality and even -36 for migrant influx.

Similar transformations could be observed in all surveyed countries. For instance, almost all Balkan's societies, swinging from tolerance to intolerance, are accompanied by some postsocialist countries like Hungary, Poland, Slovakia, Latvia, Lithuania. From the selected six only Slovenia and Croatia stay tolerant regardless of the specific target. The highest intolerance level we measured was in Hungary, the highest tolerance - in Iceland, Sweden, and Norway. Geographical location plays important role in the tolerance level, but it is not the only factor. National culture of accepting 'different others' in any modification, along with factors like individual and social trust, religion, standard of living, and so on, make significant impact on tolerance. The same is also true for the Balkans as a part of Europe. The six selected countries are neighbors, they have a more or less common past. Slovenia, Serbia, Montenegro and Croatia used to be part of the same federal confederation, and yet they are rather different.

There is no unified position with regards to the European attitudes to people with different sexuality, either. Northern countries like Iceland, Norway, The Netherlands, Sweden are the most tolerant to people with specific sexual orientations. At the opposite pole among the most intolerant, we find Latvia, Serbia, Montenegro, Bulgaria, Slovakia, Hungary.

As for the tolerance towards migrants, the picture is also heterogeneous. In all surveyed countries, there is a significant decrease in positive attitudes at the expense of reserves and negativity, compared to attitudes towards sexual differentiallity and abstract objects of tolerance. Italy, one of the countries worst affected by a persistent migrant inflow, records a dramatic drop in tolerance from mean +45 in abstract tolerance to mean -10 when it comes to the contribution of migrants to the country's life. Even the most open-minded Northerners express reservations about the migrant's positive impact on their country's life style.

General explanation could be, that nether Europeans, nor people in the Balkans are happy with such massive migrant waves to the continent. The decline in tolerance levels related to people with different sexuality, and to migrants, is respectively more than double even in the Northern societies, which are the most tolerant part of Europe. Those of the Balkans also dramatically reduce their tolerance in the same direction. But, while in Northern Europe, despite the significant decrease of tolerance levels and low values of perception of migrants, things continue to stay in the positive spectrum, in the Balkans the negative positions collapse to a serious intolerance degree $($ mean $=-10)$. 
Many people in the Balkans do not wish to coexist with migrants (mean $=-1$ ) and, unlike other European citizens, are highly suspicious of possible new settlers. Usually, migrant flows pass through and, do not settle in Balkan countries, but nevertheless, people in the South are not very syntonic to people outside their culture. Among the reasons for such attitude is that unlike the far North, where direct contacts with migrants are rather within the exceptions, people in the South often have face-to-face experience. Furthermore, in migrants they see a threat to their jobs and social benefits. Migrants are also suspected of being a threat to their security, cultural models, religions, moral norms, demographic composition, etc. In general, they see in 'migrant others' a threat of their life style.

To measure the factors influencing the level of tolerance in the Balkans, we ran random forest model based on 1000 regression threes (see the previous section Data and Methods). As dependent dimensions we used the previously calculated tolerance indexes and sub-indexes, and as independent variables we designed two sets from the ESS questionnaire. Implementing this statistical algorithm, we tried to answer what the relative impact on tolerance of each dimension was.

The first set of independent variables included standard socio-demographics, and the ranging of their importance for the tolerance in the Balkans could be seen in Table 4.

Table 4. Drivers of tolerance index in the six selected countries by socio-demographics* (\%)

\begin{tabular}{|c|c|c|c|c|c|c|c|}
\hline $\begin{array}{c}\text { Socio- } \\
\text { demographics }\end{array}$ & $\begin{array}{l}\text { All Balkan } \\
\text { countries }\end{array}$ & Bulgaria & Cyprus & Criatia & Montenegro & Serbia & Slovenia \\
\hline Happiness & $15 \%$ & 19 & 9 & 13 & 11 & 15 & 12 \\
\hline Life satisfaction & $14 \%$ & 15 & 7 & 11 & 14 & 16 & 8 \\
\hline Religiosity & $13 \%$ & 13 & 19 & 16 & 12 & 12 & 13 \\
\hline Living standard & $13 \%$ & 7 & 7 & 8 & 11 & 7 & 14 \\
\hline Education & $9 \%$ & 8 & 18 & 13 & 15 & 11 & 19 \\
\hline Social life & $9 \%$ & 11 & 9 & 12 & 8 & 11 & 7 \\
\hline Age & $8 \%$ & 9 & 15 & 8 & 8 & 8 & 8 \\
\hline Marital status & $6 \%$ & 5 & 5 & 8 & 6 & 7 & 5 \\
\hline Residence & $4 \%$ & 6 & 3 & 6 & 9 & 6 & 5 \\
\hline Main activity & $4 \%$ & 3 & 5 & 2 & 3 & 4 & 4 \\
\hline Sex & $3 \%$ & 3 & 2 & 4 & 3 & 4 & 3 \\
\hline
\end{tabular}


- $\quad$ Estimations are based on random forest with 1000 of regression trees, limited to 3 nodes for each tree; $\mathrm{N}=9,350$ cases

The first impression is the negligible influence of sex, domicile, marital status, and main activity on being or not being tolerant. Both men and women, pensioners and employed, married and single, living in big towns and in the countryside have similar points of view on acknowledging and accepting diversity. Age also plays an insignificant role in most Balkan's societies, except for Greeks in Cyprus. We registered that young people are more tolerant than those in mature and older age, but in the context of the whole set age importance is not so powerful. Education also has a non-uniform power of influence. The higher educated are more tolerant, compared to the lower educated people, but in the complex set the level of knowledge is less valuable than life satisfaction or happiness.

For the Balkans as a whole, the key socio-demographic influencers are happiness, life satisfaction, religiosity and living standard. However, they do not lead the ranging in all Balkan societies, nor follow one and the same order. Each of the selected societies ranks the factors in their own specific way, corresponding to their national cultural values, religious, moral norms, ethnic identity. For Greeks Cypriots and Croats, religion is among the strongest factors influencing the perception of differences, i.e., for them religious denominations are more important than living standards or personal happiness. Happiness and life satisfaction are more powerful for Bulgarians and Serbs in their standpoints on diversity than they are for Slovenians. For people in Montenegro and Slovenia education plays the strongest role, for Serbs - life satisfaction and happiness.

Tolerance manifests itself in the top-down line, usually tolerant people are with higher public positions than those with lower. In the well-being discourse, wealthy people are more tolerant compared to poorer ones. The relationship happiness vs non-happiness, and life satisfaction vs dissatisfaction are similar. One and the same factors could play different roles and have different specific relevance depending on the context and community's aspiration.

In our previous research on tolerance (Dimova at al., 2019), we discovered that sociodemographics are only a part of the important factors influencing the levels of tolerance. Socio-political, as well as the entire public environment surrounding people's live, are also significant. See Table 5. 
Table 5. Drivers of tolerance index in the selected countries by socio-political influencers (\%)

\begin{tabular}{|c|c|c|c|c|c|c|c|}
\hline $\begin{array}{c}\text { Socio-political } \\
\text { environment }\end{array}$ & $\begin{array}{c}\text { Balkans } \\
\text { in total }\end{array}$ & Bulgaria & Croatia & Cyprus & Montenegro & Serbia & Slovenia \\
\hline $\begin{array}{c}\text { Trust in national } \\
\text { institutions }\end{array}$ & 20 & 20 & 18 & 19 & 17 & 20 & 20 \\
\hline $\begin{array}{c}\text { Satisfaction of } \\
\text { democratic } \\
\text { institutions }\end{array}$ & 18 & 22 & 17 & 18 & 20 & 21 & 18 \\
\hline $\begin{array}{c}\text { Political left-right } \\
\text { engagement }\end{array}$ & 17 & 10 & 15 & 11 & 12 & 9 & 17 \\
\hline $\begin{array}{c}\text { Trust in people } \\
\text { Trust in international } \\
\text { institutions }\end{array}$ & 17 & 19 & 18 & 15 & 17 & 18 & 17 \\
\hline $\begin{array}{c}\text { Confident in } \\
\text { opportunity to }\end{array}$ & 9 & 7 & 10 & 7 & 8 & 8 & 9 \\
\hline participate in politics & 6 & 6 & 7 & 8 & 6 & 5 & 6 \\
\hline \begin{tabular}{c} 
Interest in politics \\
\hline
\end{tabular}
\end{tabular}

- $\quad$ Estimations are based on random forest with 1000 of regression trees, limited to 3 nodes for each tree; $\mathrm{N}=9,350$ cases

The credibility of national institutions - parliament, police, legal system, politicians, political parties and coalitions - has a relatively strongest impact on the level of tolerance in the Balkans. Even when people do not trust their national governments, even when they doubt their sincere concern for the country's prosperity, they are influenced by the policies imposed. When personal interest corresponds to official policy the critics to the running power is left behind. Here, we found impressive cross-national similarities in the ranging of the key factors and even of their figures. Individual trust, i.e., trust in people, also plays important role. In other words, when a person lives with the mindset of seeing the good side of people, $\mathrm{s} / \mathrm{he}$ is inclined to convey that attitude to those who are different from their life-style model. Conversely, when sees mostly the negative colors, usually is suspicious of others.

ESS data discover that compared to the rest of Europe, the population of the Balkans has a developed reflex for disobedience to power, as well as a reflex of distrusting any power. (Dimova at all., 2021). Another characteristic feature is that people on this peninsula usually blame for everything negative outside themselves, while avoiding personal responsibility. Most often, they are in the role of critics, and not of those who would take on the responsibility for anything. This is also the main reason for the negligible influence on tolerance of the interest in politics, as well as of the confidence in existing opportunity for participation in decision making. Balkan people are usually on their guard when making social contacts, and take what the government says with a pinch of salt. 
The correlation between GDP and tolerance index also indicates significant importance. (Figure 1) Citizens of Central and Northern European countries have higher GDP values and higher levels of tolerance. Among the Balkan countries relatively more tolerant are those with higher GDP - Slovenia and Croatia. Montenegro, Serbia and Bulgaria fall into the quadrant of the least tolerant and with the lowest GDP. Greek people in Cyprus are between the two groups.

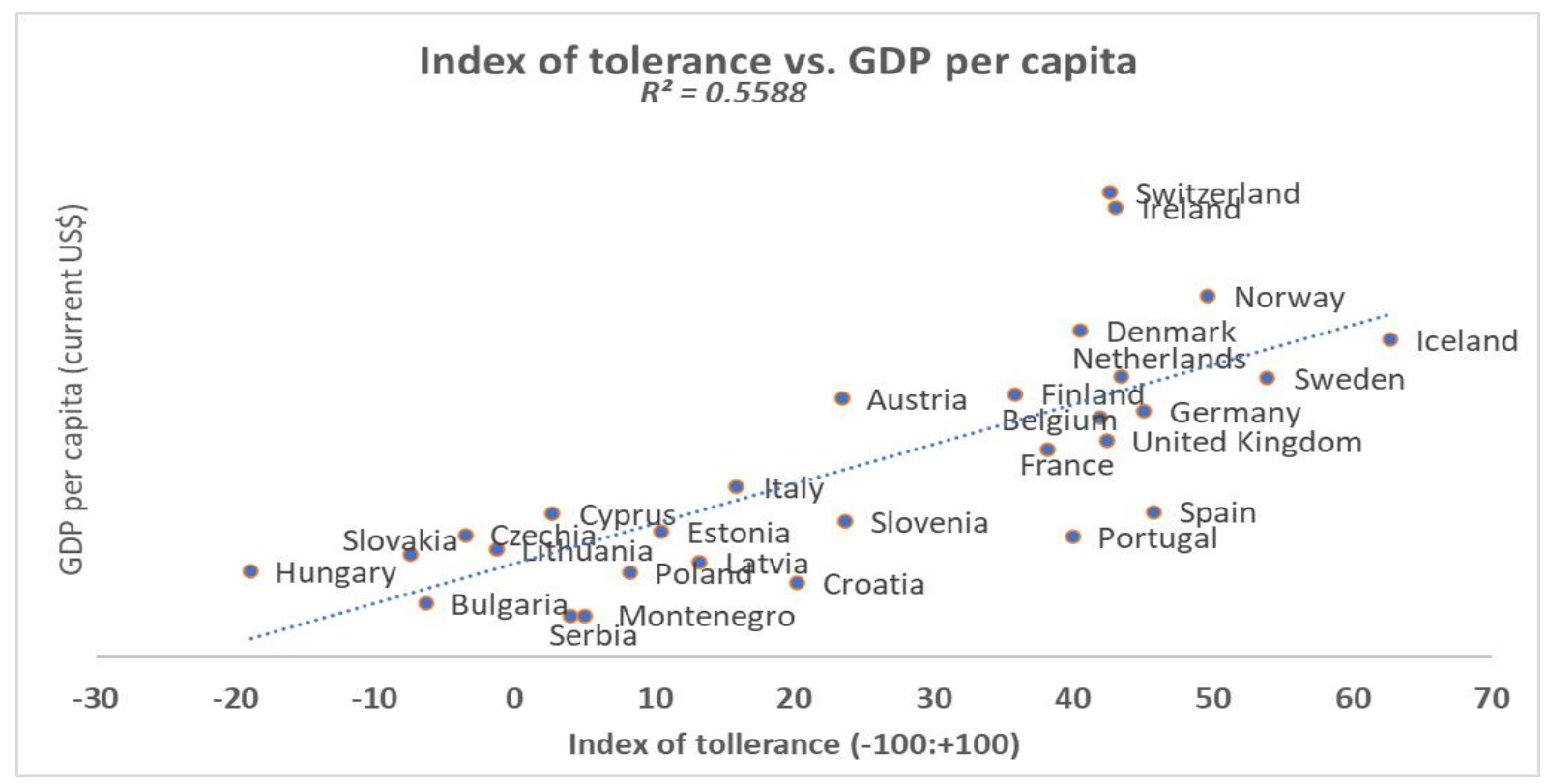

Figure1. Index of tolerance versus GDP per capita by all 29 ESS surveyed countries

The main conclusion is that the GDP as a combined measure of the living standard plays a significant role for a person, a community, and a country to be tolerant.

\section{Discussion}

In this study we focused to whether and to a what extent people in the Balkans are tolerant to different ones, keeping in mind that they themselves are an inhomogeneous mixture of cultural and ethnic diversities. We hypothesized and empirically proved that even though economic development and generational replacement made a significant cultural change, the variation in national cultural orientations is unique to each country and it inevitable puts its mark on the level of tolerance and the factors that determine it. Furthermore, we hypothesized that like the rest of Europeans, people in the Balkans are much more tolerant to abstract 'different others' than to specific tolerance targets like people with different sexuality and migrants. Hence, the US-THEM distance depends on the context. 
To test these hypotheses, we selected five Balkan countries (Bulgaria, Croatia, Montenegro, Serbia and Slovenia) and also the Greek part of Cyprus, presuming that Greek people are Greeks everywhere and observe their national cultural model, whether they live in their own country or make up the main segment of another one.

In our conceptualizations of tolerance, we kept in mind both classical (endurance and condoning) and modern (prejudiced and racist) understanding of the phenomenon (Verkuyten at al., 2021). We also share the point of view that tolerance is an abstract value orientation towards difference and does not always capture attitudes towards specific out-groups, ideas, culture or behaviour. Furthermore, we agreed with the understanding that tolerance is a multidimensional construct which combines several interconnected components.

We distinguished four interconnected dimensions of the tolerance phenomenon:: 1) perception of diversity - i.e., understanding the 'different others'; 2) recognition of diversity - i.e. a person recognizes the rights of people with different life style, believes, persuasions, sexual orientations, religion, culture norms, life priorities, etc. to live as they wish.; 3) appreciation/evaluation of diversity - i.e. a possible contribution of differentiation to establishment of a better society is respected; 4) acceptance of diversity - i.e. a willingness to live along with people who are different is declared.

Based on the above conceptual framework and its operationalization by the ESS research instruments (ESS Round 9, 2018), we measured the level of tolerance and the main influencers on these levels at both national and a comparable cross-national perspective. To do that we calculated tolerance indexes and ran random forest algorithm. As a result, we proved our hypotheses, that the Balkans are a heterogenic part of Europe where every single country of the neighborhood experiences different levels of tolerance. We also discovered that all ESS studied countries are tolerant in an abstract form, i.e., all of them declare a standpoint of understanding and pensive diversity, to recognize the right of the different to be different. In other words, according to the classical meaning of tolerance, all Europe, including the Balkans, are in the tolerant quadrant. However, people on and around the Balkan Peninsula are more abstract and less focused tolerant to the 'others' compared to the rest of Europeans. Within the Balkans we registered different levels of abstract tolerance which are the highest in the Greek part of Cyprus (with mean value $=+66)$, in Slovenia $(+63)$, in Croatia $(+59)$. Serbia and Montenegro also have high levels of abstract tolerance (means $=$ over +50 ), and Bulgaria is at the position of mean $=+31$. 
Going deeper, moving from abstract to specific tolerance objects like people with different sexuality and migrants, our study discovered significant lowering in the range of tolerance in all studied ESS countries. Regarding people with different sexual orientations, relatively most tolerant in Europe are the Northern countries like Iceland, Norway, Sweden with means up to +85. At the opposite pole, among the most intolerant could be seen Latvia (mean $=-36$ ), Slovakia (-18), Hungary (-15). From the selected Balkan countries only Slovenia and Croatia fall in the tolerant quadrant. The rest are in the intolerant section under zero with mean values of -30 for Serbia, -23 for Montenegro, - 19 for Bulgaria and -6 for Greece. Obviously, for Balkan's people, different sexual orientation is far from their traditional sexual culture.

As for the attitudes to migrants, we discovered two levels of tolerance depending on their appreciation or acceptance. Across all Europe, people do not hold a high positive opinion of the migrants' contribution to the countries' economies, cultures, and lifestyles. The average mean of tolerance in Europe is only +6 . Balkan societies have even lesser values in that aspect - in total, their mean values are -10 . The highest intolerance of appreciation of diversity is demonstrated by Bulgarians, followed by Serbians, Greeks and Montenegro.

It is interesting that the tolerance component of acceptance of diversity (i.e., willingness to coexist with migrants) is relatively high, compared to appreciation of migrants' contribution to economy and culture, and their possible role to make the country a better place to live. For all the studied 23 European countries the average mean is +17 , while for the Balkans it is -1 . In other words, most of Europeans do not think that migrants could change their country to a better place, but despite that, every sixth of them does not mind living along with some new settlers (however, if mostly of them are from the same ethnos as the majority of their society). Such willingness tends to be more a matter of selecting the 'right features', and empathy rather than an agreement foreigner to become a part of their world. Migrants would continue being 'outsiders' even among the most tolerant North, while for the large proportion of the Balkans population, they would be much less welcomed. The fear is that a migrant tsunami will financially burden their countries, could deteriorate the cultural image and change the demographic picture of their orderly societies.

The Random Forest model, based on 1,000 regression trees, found that there are no two Balkan societies with one and the same ranging of influencers on tolerance levels. All six are different in impact values (Table 3 and Table 4). Among the most powerful common vectors on the degree of tolerance results discovered happiness, living standard and religion, as well trust in national institutions. The strength of each impact factor depends on the national socio- 
cultural environment. If for Slovenia and Montenegro the leading factor is education, for Croats and Greeks it is religion, for Serbia and Bulgaria - happiness and life satisfaction. Another common denominator is the relatively weak weight of age, domicile and especially sex. Regardless of the differences in the ranking, however, the discrepancies are more in the nuances than in substance. For all people on the peninsula, the most powerful factor that affects them to be or not to be tolerant, is to what extend they are satisfied with their life in general and with the way their respective national institutions work. The Balkans selectively follow national policy of their officials, although they generally have low confidence in them. A specific characteristic of the Balkan people is their well-developed reflex of distrust and suspicion - of power, of institutions, of people. (Tilkidjiev at al., 2010) They are reluctant to participate in the governance of their own countries and to influence the decision-making. The political apathy also does not affect their tolerant or intolerant attitude towards social diversity. However, when their values and moral norms coincide with government policies towards migrants and people with non-standard sexual orientation, their criticism of state institutions become secondary.

We discovered a strong correlation between the living standard (represented by the GDP per capita) and the overall level of tolerance. It is valid for all ESS studied countries (Figure 1). The main conclusion is that the GDP and respectively the standard of living play significant role for an individual, as well as for a community and for a whole country, whether to be tolerant or not.

Generally speaking, tolerance cannot be accepted unambiguously - neither meaningfully nor morally. It should be kept in mind that tolerance is among the rare social phenomena that have both positive and negative moral dimensions - depending on the context, moral compass and target, open-mindedness may be something good or bad. Tolerance could also help overcome or deepen the social inequalities in society, depending on the willingness of the dominant group to respect the tolerated people, instead of only giving them the chance to be themselves. Being a tolerant does not always mean being something more than the tolerated ones. Even in a claiming to be a tolerant society, the targets of tolerance hardly feel like an equivalent part of it. How Verkuyten (Verkuyten at al., 2020) argues, the situation from the tolerance targets perspectives looks differently and usually means 'tolerated but not equal' (Insel 2019). The tolerated communities usually retain their positions as a minority, often even marginalized community, living by their own specific rules, and the dominant 'tolerant' group simply exhibits stand to them. The distanced of forbearance of 'the others' Galleotti labels 
'disrespectful tolerance' (Galleotti 2015). These aspects of tolerance were beyond our current field of research interest, but would be in the future. In a nutshell, the shortest answer of our current research question 'Are the Balkans tolerant?' is 'Yes, but not quite'.

\section{References}

[1] Blommaert, J. \& J. Verschueren, (2020). Debating Diversity: Analysing the Discourse of Tolerance. 10.4324/9780203029275.

[2] Breiman, L. (2001). "Random Forests". Machine Learning. 45 (1): 5-32

[3] Brown, W. (2006). Regulating aversion: Tolerance in the age of identity and empire. Princeton University Press.

[4] Campbell, B. \& Manning, J. (2018). The rise of victimhood culture: Microaggression, safe spaces, and the new culture wars. Palgrave Macmillan.

[5] Carson, D. A. (2012). The intolerance of tolerance. Eerdmans. Crossman, Ashley. (2020) "The Concept of "Other" in Sociology." ThoughtCo, Aug. 27, 2020, thoughtco.com/concept-of-other-in-sociology-3026437.

[6] Crossman, A. (2020). "The Concept of "Other" in Sociology." ThoughtCo, Aug. 27, 2020, thoughtco.com/concept-of-other-in-sociology-3026437.

[7] Dimova, 1. and M. Dimov (2019) Dynamic of 'US' to 'THEM' tolerance at European context (2013 - 2017). Report presented at the 4th International ESS Conference „Turbulent Times in Europe: Instability, Insecurity and Inequality “, Mannheim 15-17 April 2019.

[8] Dimova, L. and M. Dimov (2021) Religion and Ethnicity: Paradoxes and Scientific Challenges, International Journal of Sociology, DOI: 10.1080/00207659.2021.1964273

[9] Dimova, L. and M. Dimov. (2019) Is Europe happy? An innovative attempt to evaluate it. In Človek a spoločnost' [Individual and Society], 2019, roč. 22, č. 4, s. 42-62. doi: http://doi.org/10.31577/cas.2019.04.562

[10] ESS Round 9: European Social Survey Round 9 Data (2018). Data file edition 3.1. NSD Norwegian Centre for Research Data, Norway - Data Archive and distributor of ESS data for ESS ERIC. doi:10.21338/NSD-ESS9-2018.

[11] Ferrar, J. W. (1976). The dimensions of tolerance. The Pacific Sociological Review,19(1), 63-81.

[12] Forst, R. (2013). Toleration in conflict. Past and present, C. Cronin (trans.). Cambridge: Cambridge University Press. 
[13] Forst, R. (2017). Toleration. In E. N. Zalta (Ed.), The Stanford encyclopedia of philosophy (Fall 2017

Edn.). https://plato.stanford.edu/archives/fall2017/entries/toleration/.

[14] Galleotti, A. E. (2015). The range of toleration: From toleration as recognition back to disrespectful tolerance. Philosophy and Social Criticism, 41, 93-110. doi:10.1177/0191453714559424 SAGE Journals | ISI

[15] Hjerm, M., Eger, M.A., Bohman, A. et al. (2020). A New Approach to the Study of Tolerance: Conceptualizing and Measuring Acceptance, Respect, and Appreciation of Difference. Soc Indic Res 147, 897-919 https://doi.org/10.1007/s11205-019-02176-y

[16] Insel, A. (2019). Tolerated but not equal. Philosophy and Social Criticism, 45(4), 511515. doi:10.1177/0191453719831332

[17] Kenton, B. ed. (2013). “Generalized other” In Open Education Sociology Dictionary. https://sociologydictionary.org/generalized-other/.

[18] Martela, F., \& Ryan, R. M. (2016). Prosocial behavior increases well-being and vitality even without contact with the beneficiary: Causal and behavioral evidence. Motivation and Emotion, 40(3),351-357. https://doi.org/10.1007/s11031-016-9552-z

[19] Tilkidjiev, N. and L. Dimova (eds) (2010) Well-being and trust: Bulgaria in Europe? (Comparative Analyses on ESS Rounds 2006/2009 data). Sofia: East-West Publishing House. (In Bulgarian)

[20] Verkuyten, M. and R. Kollar. 2021. Tolerance and intolerance: Cultural meanings and discursive usage. https://doi.org/10.1177/1354067X20984356

[21] Verkuyten, M., Yogeeswaran, K., Adelman, L. (2020). The negative implications of being tolerated: Tolerance from the target's perspective. Perspectives on Psychological Science, 15(3), 544-561. doi:10.1177/1745691619897974

[22] Witenberg, R. 2014. Tolerance is more than putting up with things: it's a moral virtue, https://theconversation.com/tolerance-is-more-than-putting-up-with-things-its-a-moralvirtue-31507 